\title{
Optimalisasi Smart Blind Stick Dengan Atmega 328
}

\author{
Lukmanul Khakim ${ }^{1}$, Arif Rakhman ${ }^{2}$ \\ Email: khakimthy@gmail.com ${ }^{1}$, cakrakirana7@gmail.com² \\ DIII Teknik Komputer Politeknik Harapan Bersama
}

\begin{abstract}
Abstrak
Mata merupakan panca indera yang sangat penting untuk makhluk hidup, terutama untuk manusia. Dengan mata, seseorang dapat melihat beberapa benda, keindahan alam yang berada disekelilingnya. Jika manusia memiliki kekurangan fungsi pada panca indera terutama mata, maka akan sangat mengganggu aktifitas, manusia akan kesulitan untuk mengetahui benda atau sejenisnya, hal ini akan mengakibatkan luka atau cidera jika menabrak atau tersandung benda yang berada di depannya, oleh sebab itu didalam penelitian ini akan dibahas tentang suatu alat bantu yang berbasis mikrokontroller dan sensor ultrasonik disertai dengan motor getar di mana alat tersebut akan dirancang untuk membantu memberikan informasi kepada manusia jika di depannya ada benda. Informasi yang diberikan dari alat tersebut adalah suara dan disertai dengan getaran. Dari hasil pengujian alat tersebut didapatkan hasil jika jarak alat dengan benda di depannya berjarak $105 \mathrm{~cm}$ suara akan mulai berbunyi disertai getar dengan waktu jeda 1 detik, dan pada jarak $15 \mathrm{~cm}$ suara akan berbunyi panjang disertai getar, bunyi panjang dan getar akan berpindah menjadi dijeda jika jarak alat dengan benda lebih dari $15 \mathrm{~cm}$.
\end{abstract}

Kata kunci : Mata, Mikrokontroller, Suara, Getar

\section{Pendahuluan}

Tunanetra di dalam kamus besar bahasa indonesia (KBBI) berasal dari dua kata, yaitu "tuna" dan "netra", di mana kata tuna memiliki arti rusak atau cacat, sedangkan kata netra memiliki arti mata, maka jika digabungkan kedua kata tersebut akan memiliki arti cacat atau rusak penglihatan. Tunanetra adalah orang yang indera penglihatannya memiliki keterbatasan atau tidak sempurnanya indera penglihatan untuk melihat sekeliling[1]. Seseorang yang rusak penglihatannya secara total dapat dikategorikan orang buta. Para medis secara umum mendefinisikan bahwa tunanetra adalah seseorang yang ketajaman sentralnya berkisar 20/200 feet atau dapat diartikan bahwa daya penglihatannya hanya berkisar kurang dari atau sama dengan 6 meter, dan jarak sudutnya kurang dari atau sama dengan 20 derajat. Hanya orang yang dapat dikatakan normal jika mampu melihat pada jarak 60 meter atau 200 kaki dengan jelas[2].

Panca indera merupakan alat atau sensor yang terdapat di dalam tubuh manusia yang sangat penting keberadaanya untuk menopang fungsi-fungsi yang dibutuhkan oleh manusia.

Komposisi daya serap panca indera dibagi beberapa prosentase sebagai berikut: indera prosentase daya penglihatan $82 \%$, pendengaran $11 \%$, peraba $3,50 \%$, perasa $2,50 \%$, dan penciuman 1\%[3]. Karena komposisi prosentasenya yang sangat tinggi, maka penglihatan atau panca indera mata amat sangat penting kedudukannya dibandingkan dengan panca indera yang lainnya, bisa dibayangkan jika penglihatan kita terganggu atau tidak berfungsi sama sekali, pastinya akan membuat manusia kesulitan dalam melakukan segala aktifitasnya sehari-hari. Oleh karena itu panca indera mata haruslah dijaga agar fungsinya selalu dapat kita nikmati.

Mikrokontroller merupakan sebuah sistem yang didalamnya terdapat central processing unit $(\mathrm{CPU})$, random access memory (RAM), read only memory (ROM), inputoutput $(\mathrm{I} / \mathrm{O})$, clock dan peralatan internal lain yang sudah saling terintegrasi di mana komponen tersebut sudah dikemas menjadi sebuah chip yang sudah siap dipakai[4]. Arduino uno Atmega 328 merupakan board yang tergolong dalam mikrokontroller di mana menggunakan mikrochip Atmega 328 yang memiliki 14 kaki I/O digital dan 6 kaki analog atau PWM[5].

Berdasarkan latar belakang masalah yang sudah dijelaskan, maka tujuan penelitian ini adalah terciptanya sebuah alat bantu berbasis mikrokontroller atmega 328 untuk penderita tunanetra agar dapat beraktifitas layaknya orang yang normal atau tidak mengalami tunanetra, supaya mereka tidak bergantung pada orang lain dalam hal berjalan atau mencari arah jalan yang tidak terjal dan berpotensi membuat cidera fisik atau kecelakaan yang berakibat fatal. 


\section{Metode Penelitian}

Dalam melakukan penelitian ini, metode yang digunakan adalah dengan metode deskriptif, atau suatu metode penelitian yang dilakukan berdasarkan kejadian atau fenomena yang terjadi pada saat ini.

Langkah pertama yang dilakukan dalam perancangan smart blind stick dengan Atmega 328 adalah mempersiapkan komponen dan peralatan pendukung lainnya, antara lain:

1. Arduino UNO 328,

2. Sensor Ultrasonik HC-SR04,

3. Buzzer Aktif,

4. Motor Vibrator,

5. Baterai $9 \mathrm{~V}$,

6. Saklar ON/OFF,

7. Kabel Jumper.

Selanjutnya komponen tersebut dirakit sesuai dengan diagram pada Gambar 1.

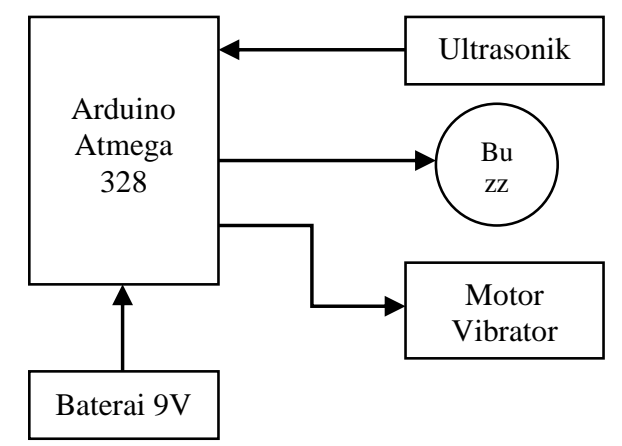

Gambar 1. Diagram Blok Smart Blind Stick dengan Atmega 328

Dengan menggunakan diagram blok pada Gambar 1, maka dapat digambarkan diagram alir pada Gambar 2.

Cara kerja dari smart blind stick dengan Atmega 328 adalah ketika sensor ultrasonik HC-SR04 memancarkan sinyal ultrasonik pada bagian transmitter atau pengirim dan mengenai objek yang berada di depannya, maka sinyal tersebut akan dipantulkan kembali ke sensor ultrasonik HC-SR04 pada bagian receiver atau penerima, dengan kembalinya sinyal ultrasonik tersebut, maka dengan menggunakan perhitungan yang sudah ditanamkan kedalam sistem arduino, jarak antar objek dengan sensor ultrasonik HC-SR04 akan diketahui, sehingga jika jarak yang terdeteksi pada sensor ultrasonik HC-SR04 $105 \mathrm{~cm}$, maka buzzer akan berbunyi beep 1 kali disertai getaran yang dihasilkan dari motor vibrator.

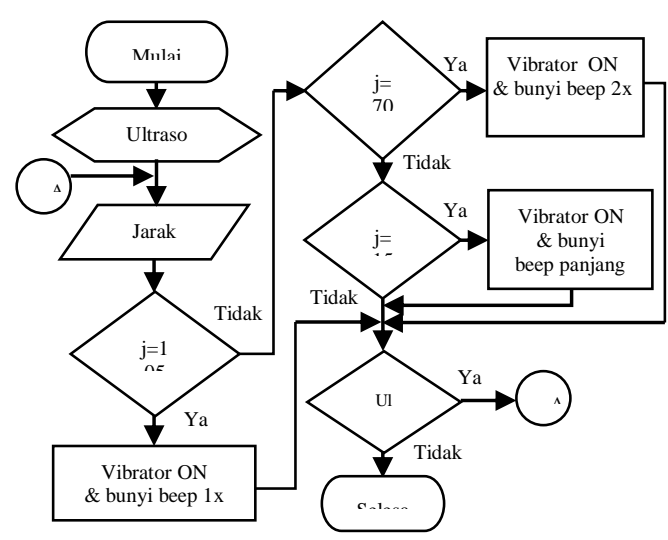

Gambar 2. Diagram Alir Smart Blind Stick dengan Atmega 328

Ketika jarak terdeteksi $70 \mathrm{~cm}$, maka buzzer akan berbunyi beep 2 kali disertai getaran yang dihasilkan dari motor vibrator. Sedangkan ketika jarak terdeteksi $15 \mathrm{~cm}$, maka buzzer akan berbunyi beep panjang disertai getaran yang dihasilkan dari motor vibrator.

\section{Hasil dan Pembahasan}

Setelah proses perancangan dan perakitan telah selesai dilakukan, maka langkah selanjutnya adalah melakukan pembahasan tentang hasil pengujian alat atau projek smart blind stick dengan atmega 328. Berikut merupakan gambar nyata dari smart blind stick dengan atmega 328, ditampilkan pada Gambar 3.

Total panjang dari Smart Blind Stick adalah $80 \mathrm{~cm}$, dengan box tempat untuk mikrokontroller $12 \mathrm{~cm}$ dan lebar $6 \mathrm{~cm}$. Di dalam box tersebut terdapat beberapa komponen penyusun smart blind stick, penampakan komponen tersebut dapat dilihat pada Gambar 4.

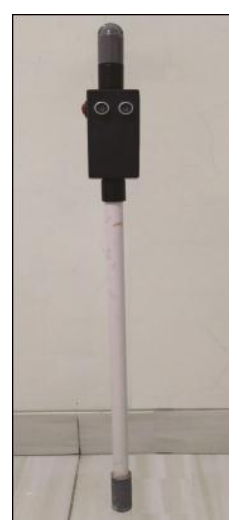

Gambar 3. Smart Blind Stick dengan Atmega 328 


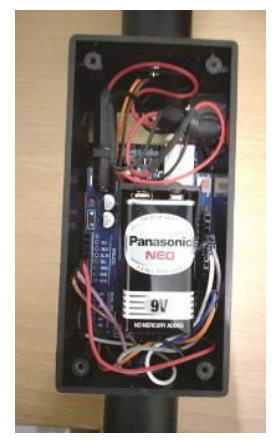

Gambar 4. Penampakan Instalasi Smart Blind Stick

Dalam proses pengujian fungsi alat, langkah-langkahnya adalah sebagai berikut:

1. Nyalakan smart blind stick dengan menekan tombol power yang berada disamping box, alat sudah dapat digunakan ditandai dengan nyala lampu merah pada tombol power,

2. Arahkan sensor ultrasonik yang berada di depan box ke arah objek atau tembok secara perlahan-lahan dekatkan alat dengan objek tersebut hingga terdengan bunyi beep disertai getar pada smart blind stick,

3. Ulangi langkah no 3 untuk mendapatkan hasil jarak yang berbeda, ditandai dengan bunyi beep dan getar yang berbeda pada masing-masing jarak.

Untuk hasil pengujian alat dapat dilihat pada tabel pengujian pada Tabel 1 .

Dari hasil pengujian yang disajikan dalam Tabel 1, di mana pengujian dilakukan sebanyak enam kali percobaan dengan jarak objek yang berbeda-beda. Hasil pengujian no 1 dapat dilihat jarak sesungguhnya antara objek dengan smart blind stick adalah $110 \mathrm{~cm}$, sedangkan pada hasil pengukuran dengan sensor adalah $108 \mathrm{~cm}$, selisih $2 \mathrm{~cm}$, dan pengujian 2 dan 3 didapatkan selisih $1 \mathrm{~cm}$ dan $2 \mathrm{~cm}$, sedangkan pada pengujian ke 4,5 dan 6 , hasil pengukuran jarak secara manual dengan menggunakan sensor hasilnya adalah sesuai, atau tidak ada selisih jarak dari kedua cara pengukuran tersebut.

Tabel 1. Hasil Pengujian

\begin{tabular}{|c|c|c|c|c|}
\hline \multirow{2}{*}{ No } & \multicolumn{2}{|c|}{ Jarak(cm) } & \multirow{2}{*}{ Buzzer } & Vibrator \\
\cline { 2 - 4 } & Nyata & Alat & Tidak & $\begin{array}{c}\text { Tidak } \\
\text { Aktif }\end{array}$ \\
\hline 1 & 110 & 109 & $\begin{array}{c}\text { Aktif } \\
\text { Aktif 1 }\end{array}$ & Aktif 1 \\
\hline 2 & 105 & 104 & Aktif 2 \\
\hline 3 & 75 & 73 & Aktif 2 & Aktif 3 \\
\hline 4 & 50 & 50 & Aktif 3 & Aktif 3 \\
\hline 5 & 35 & 35 & Aktif 3 & Aktif 4 \\
\hline 6 & 15 & 15 & Aktif 4 & Aktif 4 \\
\hline
\end{tabular}

Keterangan:

Aktif 1 : Bunyi Beep 1 kali dan Getar 1 kali.

Aktif 2 : Bunyi Beep 2 kali dan Getar 2 kali.

Aktif 3 : Bunyi Beep 3 kali dan Getar 3 kali.

Aktif 4 : Bunyi Beep dan Getar kontinyu.

Untuk pengujian ke 1, buzzer dan getar tidak aktif, karena jaraknya diatas $105 \mathrm{~cm}$ atau jarak aman, sedangkan pada pengujian ke 2, buzzer berbunyi beep satu kali disertai getaran satu kali, pada pengujian ke 3, buzzer berbunyi dua kali disertai getaran dua kali, sedangkan pengujian ke 4 dan 5 buzzer berbunyi tiga kali disertai getaran sebanyak 3 kali, dan pada pengujian ke 6 , buzzer berbunyi panjang dan disertai getaran yang panjang pula.

\section{Kesimpulan}

Dari hasil pengujian yang telah dilakukan, maka didapatkan beberapa kesimpulan yang dari penelitian ini antara lain:

1. Ketepatan sensor ultrasonik dalam menghitung panjangnya jarak antara sensor dengan objek pada jarak diatas $75 \mathrm{~cm}$ mengalami selisih antara $1 \mathrm{~cm}$ sampai $2 \mathrm{~cm}$.

2. Kinerja sensor ultrasonik mulai stabil jika jaraknya $50 \mathrm{~cm}$ kebawah.

3. Karena kesederhanaan desain dan pengontrolnya, menjadikan smart blind stick mudah digunakan tanpa harus belajar atau training terlebih dahulu, karena hanya terdapat satu tombol yang berfungsi untuk mengaktifkan dan menonaktifkan alat.

\section{Daftar Pustaka}

[1] R. N. Muthmainnah, "Pemahaman Siswa Tunanetra (Buta Total Sejak Lahir Dan Sejak Waktu Tertentu) Terhadap Bangun Datar Segitiga," J. Pendidik. Mat. Mat., vol. 1, no. 1, pp. 15-27, 2015, [Online]. [2] A. Hidayat and A. Suwandi, Pendidikan Anak Berkebutuhan Khusus Tunanetra. Jakarta Timur: PT. Luxima Metro Indah, 2013.

[3] Rakhman, A., \& Sabanise, A. Y. F. (2019). Sistem Informasi Stok Kebutuhan Darah Pada Palang Merah Indonesia Dengan Metode Weighted Moving Average. Syntax Literate; Jurnal Ilmiah Indonesia, 4(7), 24-32.

[3] P. Wiroatmojo and Sasonoharjo, Media Pembelajaran. Jakarta, 2002.

[4] A. Bejo, $C$ dan AVR: Rahasia Kemudahan Bahasa $C$ dalam Mikrokontroller ATMega 8535, 1st ed. 
Graha Ilmu, 2008.

[5] A. Febtriko, "Sistem Kontrol Perternakan Ikan Dengan Menggunakan Mikrokontroller Berbasis Android," $J$. Teknol. dan Sist. Inf. Univrab, vol. 2, no. 1, pp. 21-31, 2017, [Online]. Available: http://jurnal.univrab.ac.id/index.php/rabit/ article/download/148/97/.

[6] Rakhman, A., \& Rais, R. (2020). Analisa Pakan Burung Otomatis Menggunakan Arduino Berbasis Internet Of Things. Syntax Literate; Jurnal Ilmiah 